\title{
Analysis on the Current Situation of Tourism English Major in Universities and the Application of ETP Training Mode
}

\author{
Hong Liu \\ Yunnan Agricultural University, Kunming, Yunnan, 810008
}

\begin{abstract}
With the acceleration of the process of economic globalization, English has become one of the hottest majors in colleges and universities. Tourism English, as the most practical value of English major, is a combination of tourism and English professional characteristics of the two professional, with high employment value, as many students choose one of the highly respected. At the same time, in the process of developing tourism English, how to cultivate innovative talents and establish innovative talents training mode in colleges and universities has also become a problem that must be solved in tourism English majors. Therefore, we will also study and analyze the present situation of tourism English major in colleges and universities and the application of EPT talent training mode.
\end{abstract}

Keywords: University, tourism English, ETP, talent training model

\section{Introduction}

With the continuous improvement of cultural tourism consumption level, the expansion of English demand market, tourism English professional requirements are also rising. In order to adapt to the social and economic development, it is necessary to improve the level of tourism English education, change the mode of tourism English classroom education, and ultimately improve the level of development of the overall tourism English in China [1]. In the development of tourism English at the same time, for the tourism English training, but also improve the industry's inevitable choice. ETP talent training model is a new 
thinking and new way of talent cultivation. Through the division of the stage, the goal of long-term talent training is designed as short-term and continuous upward process, which makes the process of talent cultivation more concrete and controllable. It achieves the formation of personnel training model. In the course of tourism English teaching in colleges and universities, learning to use ETP talent training mode is also an important driving force for the development of tourism English major in colleges and universities.

English is our daily or career development, we must master the professional skills. Its use is in the life and workplace, far greater than we think. Whether it is daily cultural exchange, tourism, film and television appreciation, or workplace business communication, product learning, will be used in English. Tourism English, as one of the major branches of the application development of English is representative. Tourism English has the characteristics of integration, is the tourism industry and the integration of English professional development from the cross. The integration of these characteristics makes the requirements of tourism English professional in the university constantly upgrading, whether it is daily classroom education, classroom teaching reform, or the strengthening of teaching practice, are the inevitable development of tourism English professional process.

\section{The professional status of tourism English}

\subsection{Emphasis on teaching content theory}

Although the tourism English majors still maintain rapid development, there still exist many problems in their classroom teaching. Teaching content is too emphasis on theory, teaching practice is not strong, resulting in slow progress in teaching, teaching results are not ideal, students can not really grasp the content of learning from a practical point of view. And the loss of teaching practice, resulting in increased boring content of teaching, virtually increased the pressure of student learning English tourism. Tourism English course itself is a practical professional, in order to improve the level of development of tourism English, colleges and universities will inevitably improve the practicality of the curriculum efforts. The practical strengthening of the course is conducive to improve the employment rate of tourism English to promote tourism English professional and market convergence.

\subsection{The failure of assessment methods}

The same is the problem of tourism English professional assessment methods. The current assessment method of tourism English major in colleges and universities is the traditional examination paper, focusing on the theory of tourism English professional assessment, ignoring the practice assessment. And we know the theory of assessment, due to the drawbacks of the limitations of the assessment methods, making it easier to detect the level of the theoretical level of 
students can not determine the students ability and level of practice. However, the practicality of tourism English professional, requires the practice will become part of student learning, but also become a way of assessment. If the practice of the way of theoretical examination of test methods will inevitably lead to the failure of the test results or test scores to reduce the distinction can not really distinguish between the practical ability of tourism English students, leading students to ignore the practical ability of tourism English, resulting in tourism English practical ability Can not really be improved [2]. In terms of assessment from the point of view or from the assessment of the reverse way to promote teaching, assessment methods tend to theorize, will make the assessment is not strong enough to reach the desired assessment results, while leading to reverse the role of assessment to promote teaching Weakened.

\subsection{The rigid teaching methods}

Teaching methods are too rigid, can not attract the attention of students, the students absorb the classroom to understand the effect is not ideal has become one of the most need to overcome the ills. It is embodied in the single teaching contents and simple teaching methods. Even if students have mastered the content of the text, they only learn daily communication, and there is still a distance to achieve the English level. Teaching methods and means are too single, unilateral teaching of teachers, resulting in from the visual, auditory and even sensory aspects of arouse students desire to learn, students will naturally discount the learning effect. This shows that the current teaching process is highly dependent on the teacher, the lack of interactive teaching, student participation in classroom teaching is low, one person propped up the teaching classroom, can not mobilize the enthusiasm of students, it is difficult to improve student interest in learning. All the signs are that the rigid teaching methods, the impact of college tourism English teaching ability to enhance the key.

\section{ETP personnel training mode characteristics}

\subsection{The stage}

ETP talent training model refers to the application of personnel training, is the abbreviation of the Executive Training Program, translation is the management of applied personnel training [3]. ETP personnel training with the characteristics of the stage, the stage is the first knowledge of training, followed by technical training, the final practice of training. ETP talent training in stages, with a level, will be different professional skills are divided into three levels to teach, so that students are more receptive. At the same time, its stage also has progressive. Different stages, the actual divided into basic knowledge, skills improvement, practice testing. According to the process of learning from the students to the difficult, gradual knowledge and skills to teach, so that students more receptive to the understanding and mastery of knowledge to further improve, and the process 
will not have a strong sense of frustration. In learning the knowledge at the same time, their learning ability to continuously improve and enhance their learning self-confidence, it is easy to find fun from learning to achieve their true ability to improve, and ultimately achieve the purpose of personnel training.

\subsection{Targeted}

ETP talent training model due to the characteristics of the stage, leading to ETP personnel training model also has a strong targeted. In the process of cultivation, the first stage is for the cultivation of basic knowledge, through a series of knowledge teaching, including knowledge, knowledge sharing, and finally to master the knowledge and ability. Similarly, the second stage of skills development, the same is through various forms of video, discussion, conferences, exhibitions and other means of knowledge and skills professors to help students based on the basis of knowledge to improve the skills of students ability to use for the next step Of the practical ability to lay the foundation. In the final stage, for the students' practical ability to carry out training, to learn the basic knowledge before the use of, but also to master the skills before a practical operation and practice testing. Through the form of practice, so that students learning ability rise to a stage to improve the students' practical ability, for the future talent into the community work lay the groundwork.

\subsection{Significant}

ETP talent training model also has significant characteristics of the effect. Through the stage of personnel training and targeted knowledge and skills training, students in the study also mastered the ability to learn knowledge. We all know that to teach the fish to teach them to the network, the same reason, ETP personnel training model, not only the knowledge and skills taught, but also the ability to learn knowledge and skills. In learning at the same time, by thinking about learning efficiency and learning methods, students can learn how to learn knowledge and ability to learn a good inspiration. The process of learning focused on the stage and the skills of targeted training, including the practical operation, we are from the ETP talent training model to obtain learning skills. Knowledge at this time is the second, whether to learn and master the knowledge is the ability to learn the true strength of the performance of learning ability is also the future career development career, the most important spiritual wealth. .

\subsection{Extensive}

ETP talent training model has a wide range of applications in society. At the same time ETP training mode, but also tourism English teaching should be a large number of applications of teaching knowledge and ability training methods. In the enterprise management, ETP talent training mode has also been widely used, of course, is due to ETP talent training model is reasonable and significant efficiency. In the tourism English professional personnel training, learn to use this way for teaching is also an important way to improve teaching results. And 
how to apply this model, not only requires its penetration throughout the tourism English professional learning, but also should be in each course of study, each specific course of study. The whole course of tourism English training at the same time both ETP talent training model in the implementation of decentralized curriculum, and ultimately to help students really progressive, regular and efficient grasp of tourism English knowledge and ability to improve the level of tourism English education, Enhance the professional ability of tourism English students.

\section{The application of ETP training mode in tourism English}

\subsection{Pay attention to tourism English training stage}

This paper discusses the characteristics of many ETP training models, then how to apply ETP training mode to the study of tourism English major in colleges and universities, which is a thorny problem. First of all, when tourism English courses are carried out in colleges and universities, the ETP training mode focuses on the characteristics of the ETP training mode. The tourism English knowledge ability is divided into different levels. At each stage, different knowledge and skills training for students is carried out. Of the students to improve their learning ability, and promote students to steadily upgrade their professional knowledge and ability. At the same time, in the course of the whole curriculum planning, it shows different stages of the stage of color, different stages of the design of different learning methods, making learning more diversified and improve student interest in learning and motivation to entertaining To promote the students stage interest, but also on the ETP talent training mode of a strengthening and practice stage.

\subsection{Pay attention to the pertinence of tourism English training}

In addition to the ETP mode of tourism English stage of the use and learning, to strengthen the training of tourism English targeted, is also one of the ETP talent training model. Specific how to do, of course, is to enhance the tourism English training of knowledge and skills targeted. For example, in the past we have a number of courses at the same time in our teaching, different courses interspersed at different times, in the ETP talent training mode, we can be similar to the classification of curriculum integration, these similar courses in a day, Two days are different types of courses. As a result, a week to increase the diversity of different courses, but also improve the learning of students per day targeted. In the daily learning, from the curriculum targeted to improve the relevance of student learning, making the student stage of the course to enhance the perception of ability, while the integration of the stage and targeted characteristics. 


\subsection{Pay attention to the training of tourism English Talent Effectiveness}

Pay attention to the effectiveness of tourism English training, but also to ensure the quality of tourism English teaching in the top priority. ETP talent training mode, it is learning the stage or targeted, the premise are to ensure that its implementation in place, but also focus on the final assessment and practical ability to test. Not only in the learning process to improve their learning ability, while in the daily focus on the detection of learning outcomes to ensure the effectiveness of learning outcomes within the stage, and only in this case, it is possible to achieve steady improvement in learning ability. And ultimately improve students' learning ability and professional ability. The assessment criteria and methods should break the previous audit approach, using a variety of assessment methods, combined with examination papers and practice assessment, the students of all-round assessment test.

\section{Conclusion}

The current status of tourism English and the development of international tourism, require our college tourism English professional teaching transformation and innovation. Through the new ETP talent training mode, according to the characteristics of tourism English professional, students of tourism English professional training. In this process, the stages of learning, targeted training has the final practical operation, the overall improvement of students' professional learning ability, so as to improve the overall direction of the tourism English professional teaching ability, success with international practice.

\section{References}

[1] Jiang Yuansheng.Teaching English professional tourism talents training mode [J]. Vocational English Education, 2015, 5 (6): 55-56

[2] Yu Zhongwen. Higher vocational education practice teaching research [M]. Beijing: Tsinghua University Press, 2014,8 (9): 37-41.

[3] Yang Wenliang. Teaching mode of tourism English talents in vocational schools. Teacher perspective, 2012, 9 (4): 154-155 